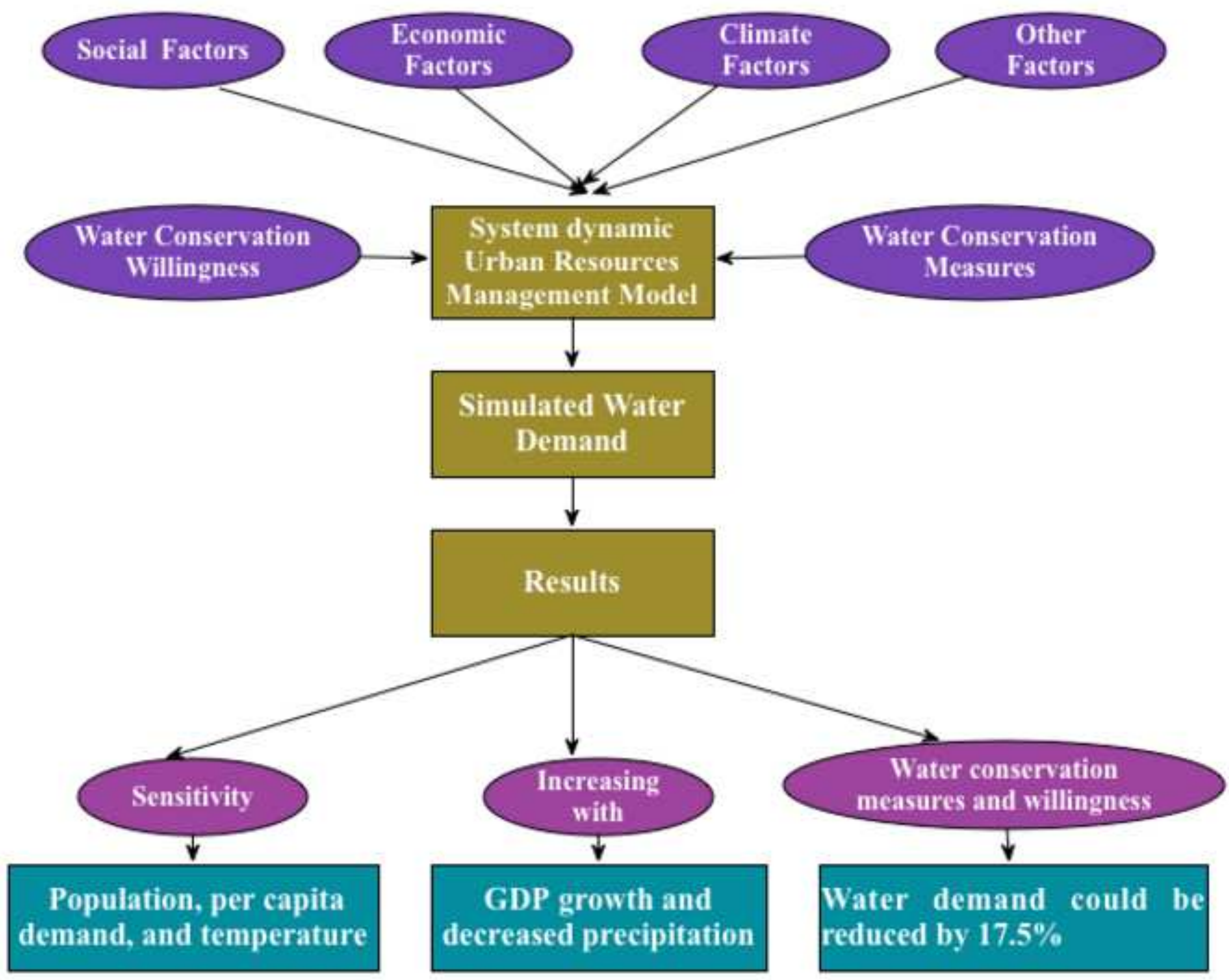

(C) 2016. This manuscript version is made available under the Elsevier user license

http://www.elsevier.com/open-access/userlicense/1.0/ 


\title{
A system dynamics urban water management model for Macau, China
}

Tong Wei ${ }^{1}$, Inchio $\mathrm{Lou}^{2}$, Zhifeng Yang ${ }^{1}$, Yingxia $\mathrm{Li}^{1, *}$

\begin{abstract}
Urban water resources have been facing significant pressure from population growth, urbanization, and climate change. A system dynamics urban water management model was proposed to simulate the dynamic interactions between urban water demands and society, economy, climate, and water conservation. The residents' water conservation willingness was incorporated in the model and water-saving effects were quantified. The simulation results for Macau showed that population size was the main driving force for urban water demand. The change of temperature and precipitation has obvious effects on the landscape water demand. The water demand output is sensitive to the change in population, per capita demand, and temperature. Increased precipitation will reduce urban water demand and increased economic growth will increase water demand. By implementing integrated water conservation measures and improved water conservation willingness, water demand could be reduced by $17.5 \%$.
\end{abstract}

Keywords: Macau; System dynamics; Water conservation willingness; Water demand

\section{Introduction}


Water scarcity is one of the most challenging issues in the world ( $\mathrm{Wu}$ and Tan, 2012). Demand for potable water is rising because of factors such as the increase in population, improvements in living standards, and increased protection of surrounding ecosystems (Bao and Fang, 2011). The consumption of fresh water varied from $1118 \mathrm{~m}^{3} /$ year capita (Malawi) to $533,754 \mathrm{~m}^{3} /$ year capita (Iceland) in 2009 (Grafton et al., 2011). A positive linear relationship was found between population size and water demand in certain studies (Vörösmarty et al., 2000). Some researchers found that water demand grew exponentially and population increase was one of the most important reasons for this (Giuliani et al., 2013). Urban areas face an even more challenging situation of water scarcity because of rapid urbanization (Eckert and Kohler, 2014) with rapid population increase in cities. The increase in urban water users (Rozos and Makropoulos, 2013) and the per capita growth in water consumption of urban residents (Wu and Tan, 2012) all lead to substantial increases in water demand. In 2012, 40\% of the world's population suffered water shortage problems, and most cities in the world were seeking more efficient management of water resources to relieve water scarcity issues (Fahs et al., 2013).

Climate change is believed to have certain negative impacts on water resources management (Dawadi and Ahmad, 2012), accelerating the frequencies of extreme events such as floods and droughts, and increasing water demand for irrigation (Iglesias et al., 2011). The negative impact of climate change will become more severe over time. In 2030, the urban area potentially affected by climate change would be $5.55 \%-20.37 \%$ of the total urban area (Humpenoder et al., 2015). Specific methods were invented and applied to access these effects. Methods such as demand-side management and principal components analysis were used to investigate the effect of changing climatic conditions on water resources (Dawadi and Ahmad, 2012). Studies showed that the influence of rainfall on water demand was very limited, while temperature showed some degree of correlation with water demand (Haque et al., 2015). Global climate change projections for the 2050s predict a temperature increase of 1.5 to $3.6^{\circ} \mathrm{C}$, and a precipitation decrease of $10 \%$ to $20 \%$ in most areas, depending on the season (Iglesias et al., 2011).

Economic development is another important issue for water management, in addition to demographics and climate change (Cheng et al., 2009). Rapid economic development, driven by various industrial activities, consumes a large amount of freshwater. Industries account for up to $80 \%$ of the total urban water consumption in developing countries (Qian, 2012). Advanced technologies are able to recycle the water and greatly reduce water consumption. The water recycle rate of petroleum and natural gas exploitation industries can reach $84 \%$, 
and the water recycle rate of ferrous metal smelting and rolling processing industry can reach 95\% (National Bureau of Statistics, 2014).

Improving water use efficiency has become an important means to reconcile limited water supplies with growing demands (Wu et al., 2015). Many studies have investigated the influences of water conservation policies and guidance, water conservation technologies, and water conservation willingness (Ahmad and Prashar, 2010). Different water conservation measures reduce water consumption in different ways. Studies show that water-saving faucets can save $30 \%-50 \%$ of water consumption, toilet water-saving appliances can save $26 \%-60 \%$ (An et al., 2014), and park sprinkling irrigation can save 35\%-70\% compared with surface irrigation (Wang and Liu, 2007). However, water conservation willingness is more difficult to quantify than the technologies, because this involves understanding the efficiency, opportunity, and impact of certain water-saving activities as well as the desire to continually reduce consumption (Dietz, 2014). Studies show that people with greater environmental and water conservation concerns will use about $24 \%$ less water than people without such concerns (Willis et al., 2011). Certain researchers evaluate people's water conservation behaviors by establishing special models or propose new parameters such as the K-Factor, which is a multivariate composite of behaviors that converge in a manner consistent with predictions from life-history theory (Tal et al., 2006). The end-use water demand modeling method is also applied to estimate water demand changes under various scenarios including price increases, housing densification, and people's conservation attitudes (Kanta and Zechman, 2014).

For the efficient management of water systems, the dynamic influences from demographics, climate, and the economy should be taken into account. Agent-based modeling $(\mathrm{ABM})$ is commonly used in social sciences to represent individual actors (or groups) in a dynamic adaptive system. Recently ABM has gained popularity in complex system analysis because of its ability to model bidirectional relationships between individual human agents and the macro behavior of the social or environmental system (Peters and Chang, 2011). Spatially and temporally explicit data can be incorporated by ABM (Chhatwal and He, 2015). Another powerful modeling tool for complex systems is the system dynamics (SD) method. In addition to the properties of $\mathrm{ABM}$, the SD model also has the capacity for linking external systems, such as the climate subsystem, to evaluate the impact of climate change on water resources (Middelkoop et al., 2001). The SD model also takes into account a larger number of components, feedback mechanisms, behavioral responses, and time lags within the system being modeled; it incorporates alternative future scenarios and local stochastic analysis and leads the trend away from making deterministic predictions (Ahmad and Prashar, 2010). 
In recent years, the SD model has been widely applied in the urban water resources management field, for example in simulating and predicting water demand variation (Cain, 2005; Koch and Vögele, 2009). In recent studies, the SD model was coupled with various influential factors to assess their effects (Peters and Chang, 2011); economic and social dimensions were the most commonly influential factors on water demand (Qi and Chang, 2011). The influences of climate change on water demand was also investigated with the SD model (Wang et al., 2014). Most previous studies only focused on one or two influential factors and did not take into considerate the impacts of all the social, economic, and climate change factors on urban water demand as well as the quantitative evaluation of water-saving effects caused by residents' water-saving willingness.

This study proposed a system dynamics urban water management model (SDUWMM), which not only considered the social and economic impact on urban water system but also took climate change into consideration. People's water conservation attitudes (willingness) were innovatively brought into the SD model to assess the impacts of the changing attitudes of the residents on an urban water system. The effects from new water-saving appliances were also evaluated in this SD model. The limitations of SDUWMM lie in its limited number of parameters therefore it is hard for it to perfectly simulate the real world. The two main objectives of this study were: (1) to evaluate how social, economic, and climate factors affect water demand; and (2) to obtain a sustainable water conservation development pattern.

\section{Materials and methods}

\subsection{System dynamics (SD)}

System dynamics is an approach for understanding the nonlinear behavior of complex systems over time using stocks, flows, internal feedback loops, and time delays (Sterman, 2000). The interconnected components and complex system behavior for urban water systems can be clearly recognized with the SD method (Rehan et al., 2011). Stock variables in SD models are the accumulations within the system, and the flow variables represent the flows in the system that result from the decision-making process. In this study, GDP, population, and per capita water demand are stocks in this SDUWMM, and represent both physical and nonphysical accumulations as shown in Eq. (1). Flows in the SDUWMM, which represent activities or actions on a stock that transport quantities into or out of a stock instantaneously or over time, include the growth of GDP, increase in population, decrease in 
population, increase in water consumption, and water conservation willingness. The relationship between stocks and flows can be described with the following integral form (Sterman, 2000):

$$
\operatorname{Stock}(t)=\int_{t_{o}}^{t}[\operatorname{Inflow}(t)-\operatorname{Outflow}(t)] d t+\operatorname{Stock}\left(t_{0}\right)
$$

where, $t_{0}$ is the initial time; $t$ is the current time; Stock $\left(t_{0}\right)$ is the value of the Stock at initial time $t_{0}$; Inflow $(t)$ and Outflow $(t)$ are flow rates into and out of a stock at time $t$.

\subsection{General framework of the SDUWMM}

Urbanization is characterized by rapid economic and population growth in cities, accompanied by rapid increase in water demand. The SDUWMM describes the impact of social, economic, climate, and other factors on urban water demand. As shown in Fig. 1, the total water demand is composed of residential, commercial, landscape, and other water demands. Other water demands include schools and parks, common areas, and any other unaccounted for uses. Gross domestic product (GDP) is a monetary measure of the value of all final goods and services produced in a period (quarterly or yearly). GDP is one of the main driving forces of commercial water demand. Precipitation and temperature affect landscape water demand directly. The dynamic relationship between the input variables of population, GDP, precipitation and temperature, water conservation willingness and measures, and the output variable of water demand is simulated in the SDUWMM. Water conservation measures usually include increasing water recycle rates, using low-flow appliances, and reducing leakage rates.

\subsection{Construction of the SDUWMM}

In this study, the SDUWMM employs SD modeling, which uses feedback mechanisms to reflect the dynamic interactions among the subsystems. Five submodels including economy, society, climate, water system and water conservation submodels are established and are represented by different sectors as shown in Fig. 2. In the proposed model, GDP can be regarded as the accumulated value caused by increasing GDP growth, and population can be regarded as the accumulated results of the change in population. It is hypothesized that residents' per capita water demand increases with growing material needs, and decreases with growing water conservation willingness. Thus, in this study, GDP, population, and per capita water demand are stocks. GDP growth, increased and decreased population, increased water demand per capita, and water conservation willingness are flows. The interaction of feedback loops is responsible for complex system behavior. When a component inside a feedback loop 
changes, the perturbation traverses along the loop and results in a change in the originating component (Rehan et al., 2011).

\subsubsection{Economy submodel}

Economic performance can be evaluated by the GDP. In the SDUWMM, the GDP growth was calculated as Eq. (2):

$$
\frac{d G(t)}{d t}=r_{g}
$$

where, $r_{g}$, is GDP growth rate (million MOP (Pataca of Macau) per year), $G(t)$ is the GDP produce at time $t$ (million MOP).

Generally, the growth of an economy is always accompanied by increasing economic water demand if no water conservation measures are applied. Thus, commercial water demand can be expressed as a linear function of GDP as Eq. (3):

$$
\mathrm{CW} \mathrm{D}_{l}=r_{c} \times G t(\not)
$$

where, CWD $t$ is the commercial water demand at time $t ; r_{\mathrm{c}}$ and $r$ are the parameters that are determined by the linear relationship between $C W D_{t}$ and $G(t)$.

\subsubsection{Society submodel}

The logistic growth model (LGM) has been proved to be useful in summarizing historical changes in population size and for short-term projections (Chu, 2014). In this study, population growth is calculated using the LGM, which is characterized by a bell-shaped probability density function and a sigmoid curve as its cumulative density function. The description function is denoted by the Eq. (4):

$$
\frac{\mathrm{d} P(t)}{\mathrm{d} t}=r_{p} P(t)\left(1-\frac{P(t)}{U}\right)
$$

where $P(t)$ is the population at time $t ; U$ is the upper limit of the population, which is determined by the space limit and environmental capacity; $r_{p}$ is the growth rate of population (per year).

Population is the key factor that determines the residential water demand. Residential water demand includes indoor water use for kitchen, laundry, and bath water demand. The residential water demand is estimated with the Eq. (5):

$$
\mathrm{RWD}_{t}=P(t) \times \mathrm{RWDC}_{t}
$$

where, RWD $t$ is the residential water demand at time $t, R W D C_{t}$ is the residential water demand per capita at time $t$.

\subsubsection{Climate change submodel}


Climate change will lead to temperature and precipitation changes. It will influences the processes of landscape water evaporation and irrigation, and ultimately affects the total water demand. In this study, climate change factors are utilized to calculate urban landscape water demand. Landscape water demand is computed by the tool of curve fitting in Matlab 2014a by considering two independent variables of $P_{r}(t)$ and $T(t) . P_{r}(t)$ is the precipitation at time $t$, and $T(t)$ is the temperature at time $t$. The optimal fitting equation is shown as Eq. (6):

$$
\mathrm{LWD}_{t}=a \times T(t)+b \times \mathrm{P}_{r}(t)+c \times T^{2}(t)+d \times P_{r}(t) \times T(t)+e \times P^{2}(t)+f
$$

where, LWD $t$ is the landscape water demand at time $t$, and $a, b, c, d, e, f$ are all regression coefficients.

\subsubsection{Water system sub-model}

The water system submodel estimates the water demand during the simulation period with the dynamic variation of population, GDP, climate change, and water conservation factors. There are two hypotheses in this submodel. First, indoor water demand is assumed to only include commercial water demand and residential water demand; second, outdoor water demand only consists of landscape water demand and other water demand. Other water demand includes schools and parks, common areas, and any other unaccounted for uses. Other water demand accounts for about 9\% of total water demand in Macau (DSEC, 20016-2012). In this submodel, other water demand at time $t$, OWD $t$ is calculated with Eq. (7).

$$
\begin{aligned}
& \mathrm{OWD}_{t}=\left(\frac{\mathrm{CWD}_{t}+\mathrm{RWD}_{t}+\mathrm{LWD}}{1-9 \%}\right) \times 9 \% \\
& \mathrm{TWD}=\mathrm{CW}_{t} \mathrm{P} \quad \mathrm{R} \mathrm{W} \mathrm{W}_{t} \mathrm{D} \quad \mathrm{L}_{t} \mathrm{~W} \mathrm{D}
\end{aligned}
$$

where, TWD $t$ means total water demand at time $t$.

The total water demand is the summation of commercial, residential, landscape, and other water demand, which is shown in Eq. (8). Commercial water demand increases with GDP growth as shown in Eq. (3). Residential water demand varies with population expansion as shown in Eq. (4) and Eq. (5). Landscape water demand fluctuates with the variation of temperature and precipitation as shown in Eq. (6).

\subsubsection{Water conservation submodel}

Consumers' choice or willingness have significant impacts on the environment (Dietz, 2014). Thus, in this water conservation submodel, it is hypothesized that residents' water demand increases with growing material needs, and decreases with growing water conservation 
willingness as shown in Eq. (9). The influences of residents' water conservation on urban water demand are hard to quantify. Researchers usually reveal the relationship between water demand and water conservation willingness through mixed technology and questionnaire surveys (Willis et al., 2011). In this study, increasing water demand per capita is calculated by Eq. (10), and water conservation willingness is assumed to have a direct linear relationship with GDP growth. The detailed relationship is shown in Eq. (11).

$$
\begin{gathered}
\mathrm{RWDC}_{t}=\mathrm{IWDC}_{t}-\mathrm{DWDC}_{t} \\
\mathrm{IWDC}_{t}=\left(\mathrm{TWD}_{t+1}-\mathrm{TWDC}_{t}\right) / P(t) \\
\mathrm{DWDC}_{t}=k \times r_{g}
\end{gathered}
$$

where RWDT $t$ represents residents' water demand per capita at time $t$; IWDC $t$ residents' increasing water demand per capita at time $t$; DWDC $t$ represents residents' decreasing water demand per capita caused by water conservation willingness at time $t ; k$ is a coefficient that is determined by the relationship between the residents' decreasing water demand per capita and the GDP growth rate.

\subsection{Study area}

Macau, located in southern China's Pearl River Delta, is one of the two special administrative regions of China. In 2013 the total area of Macau city was $31.3 \mathrm{~km}^{2}$, and the population level reached 607,500. Macau is characterized as having a typical humid, subtropical climate, with an average relative humidity between $75 \%$ and $90 \%$, a mean air temperature of $22.7^{\circ} \mathrm{C}$, and an average annual rainfall of over $2000 \mathrm{~mm}$ (DSEC (Census and Statistics Department of Macau), 2012). Because of an extremely limited land area, and rapid socioeconomic development, the gap between water resources demand and local water supply is growing. According to statistical information, water availability for each Macau resident from local sources is only about $5 \mathrm{~m}^{3} /$ day (DSEC, 2012).

Fig. 3 shows the location of the major water infrastructure, including wastewater treatment plants, pumping stations, and reservoirs. Limited by local regional space, the effective storage capacity of the two major reservoirs in Macau is only 1.9 million $\mathrm{m}^{3}$, including 1.6 million $\mathrm{m}^{3}$ in the Main Storage Reservoir, and $300,000 \mathrm{~m}^{3}$ in Seac Pai Van Reservoir. The total storage capacity can only meet Macau's water demand for a maximum of 9 days. The available groundwater resources are very limited, and are less than $1.68 \%$ of the water supply. More than $96 \%$ of the fresh water consumption of Macau comes from the Pearl 
River Delta. Household water consumption in Macau is less than $160 \mathrm{~L}$ per capita per day on average, which is less than in developed countries. Commercial water consumption is the second largest water consumption in Macau. Most hotels waste a large amount of fresh water on extravagant water features and experience less water conservation willingness from customers. Rapid economic development in upstream areas coupled with the continued strong economic growth of Macau will place Macau's fresh water supplies under greater stress in the future. Therefore, Macau needs to broaden its water resources base, as well as change its water consumption patterns.

\subsection{Implementation of SDUWMM to Macau water system}

Eqs. (2), (4), (6), and (9) provide the major components in the submodels of SDUWMM for Macau's water system. The linkage among the submodels is demonstrated by equation 8 . The input parameters of SDUWMM include GDP, GDP growth rate, population, temperature and precipitation (DSEC, 2006-2012), and water-saving appliance polarizing rate and efficiency (DSEC, 2006-2012) from 2006 to 2012. Different categories of water demand data for Macau were used to verify the output water demand and calibrate the parameters used in the model. The initial values for the parameters used in the model were determined by multiple vivification and adjustment of the values. Matlab (2014) was used to determine the linear and nonlinear relationships between the different water demands and their respective driving forces. Specific low-flow appliances for water conservation implemented in this study include: low-flow and high-efficiency flush toilets, low-flow showerheads, low-flow faucets, and water-saving irrigation. The parameters for the water-saving appliances' saving rate and leakage rate in this model were set according to Macau's water conservation plan, compiled by the Macau government. The effect of water conservation measures and water conservation willingness on the amount of total water demand was calculated with Eq. (9), (10), and (11) in the SDUWMM.

\section{Results and discussion}

\subsection{Variation in the main driving forces and the simulated results}

The input variables of the SDUWMM include GDP, population, temperature, precipitation, and integrated water conservation measures. Water demand in different categories and the total water demand will be the output of the model. The recorded values of the main driving forces of water demand for Macau during the years of 2006-2012 are shown in Fig. 4. From 
2006 to 2012, the population of Macau increased by 13\%, while the residential water consumption grew about $8 \%$ as shown in Fig. 5. Water-saving appliances were widely installed during this period. The GDP increased more than $80 \%$ during the same period, accompanied by a $64 \%$ increase in commercial water consumption. The growth of the local gambling industry was one important reason for these changes. Temperature and precipitation did not change very much in 2006-2012. The computational efficiency of this model was high with an operation time of $5 \mathrm{sec}$.

Fig. 5 shows the observed water consumption in different categories from 2006 to 2012 together with simulated water demand during the same period. From 2006 to 2012, the major water demand increase came from commercial water demand, whereas the residential, landscape, and other water demand did not increase significantly. The differences between the observed consumptions and the simulated demands were all less than 15.6\%. Further evaluation of the model validation will be discussed in the next section.

\subsection{Model validation}

During the construction of the SDUWMM, the Euler method was selected as the integration method after testing the methods of Euler (Mokhtari and Benallegu, 2004), 2nd order Rungee Kutta (Trethewey, 1990) and 4th order Rungee Kutta (Liu and Thorp, 2000), which revealed no significant differences in the results. A time step of 1 year was selected after various time steps were tested.

The model performance was evaluated using maximum relative error $(M)$ and normalized standard error $(E)$. The $\mathrm{M}$ indicates the maximum possible divergence between observed and calculated data, which characterizes the worst case model performance. The detailed calculation is shown in Eq. (12). The $E$ is defined as the square root of the variances between the observed and calculated data, which characterizes the average case of model performance (Qin et al., 2011). The detailed calculation is shown in equation (13).

$$
\begin{gathered}
M=\max \left|\frac{q_{p i}-q_{m i}}{q_{m i}}\right| \\
E=\frac{\sqrt{\frac{1}{n(n-1)} \sum_{i=1}^{n}\left(q_{p i}-q_{m i}\right)^{2}}}{\frac{1}{n} \sum_{i=1}^{n} q_{p i}}
\end{gathered}
$$

where, $q_{\mathrm{pi}}$ is the ith predicted value; $q_{\mathrm{mi}}$ is the corresponding measured value; and $n$ is the number of measurements. 
The validation results for the different water demand categories are shown in Table 1 and Fig. 5. The values of $M$ for total, commercial, residential, and landscape water demand in 2006 to 2012 range from $0 \%$ to $15.6 \%$. Most values are less than $10 \%$ with only one value larger than 10\%: the $M$ of residential water demand in 2010. This is because the population of Macau declined in 2010, whereas the population was set to keep growing in the SDUWMM. Compared with the previous studies with less factors such as Qin et al. (2011), which only had two factors of economy and society, the average $M$ value of residential water demand of this model is $1.69 \%$ less than that of Qin et al. (2011). Most E values are also less than $10 \%$, with only one exception, the E for residential water demand in 2010. Other water demand is determined by a fixed percentage of the total water demand. Thus, it has the same $\mathrm{M}$ and $\mathrm{E}$ values as the total water demand. Therefore, the SDUWMM works well for Macau's data, and the difference between the calculated water demands and the recorded values is very small.

\subsection{Uncertainty}

A sensitivity analysis and an uncertainty analysis were conducted on the SDUWMM to propagate uncertainties in the model inputs and parameters to the model output. In this study, the driving force factors of GDP, population, precipitation, temperature, and per capita water demand were explored with sensitivity analysis. The variations in the factors were set to be $\pm 5 \%$ and $\pm 10 \%$. The historical data for 2006 were utilized. Fig. 6 shows the results of the sensitivity analysis. The output of water demand is sensitive to population, capita water demand, and temperature. Small changes in these outputs will lead to clear fluctuation in water demand. The $\pm 5 \%$ and $\pm 10 \%$ change in population, per capita water demand, and temperature will result in a change in water demand of $\pm 4.8 \%$ and $\pm 9.3 \%$ for population, $\pm 4.6 \%$ and $\pm 9.3 \%$ for per capita water demand, and $\pm 4.4 \%$ and $\pm 8.5 \%$ for temperature. Future water system planning and decision-making should pay attention to these sensitive factors.

Model uncertainty is usually comprised of model structure uncertainty, parameter uncertainty, and input uncertainty (Refsgaard et al., 2007). In this study, SDUWMM is a mathematical simplification of the real physical water system under the dynamic impacts of social and climate change. This simplification process has uncertainties that account for model structure uncertainty. Parameter uncertainties also contribute significantly to the outcome of the model. In this study, temperature and precipitation have many uncertainties since extreme climate happens frequently whereas the model only uses average data for a period. In terms of the input data uncertainty, SDUWMM assumes that labor productivity and water conservation willingness change with GDP growth, and GDP growth is estimated on the 
basis of a Cobb-Douglas production function. The Cobb-Douglas production function is a particular form of the general production function, widely used to represent the technological relationship between the amounts of two or more inputs (Benchimol, 2015). The parameters in the function are estimated by nonlinear regression using data from 2006 to 2012. Lack of long-term historical data to estimate this parameter will cause uncertainties in these input parameters.

\subsection{Influences of climate change}

To further understand how climate change affects the urban water system, simulated landscape water demand versus annual precipitation and temperature are plotted as a hyperboloid surface in Fig. 6. The black points in Fig. 6 are recorded landscape water demand data. Fig. 7 shows that when the temperature rises from $22.0{ }^{\circ} \mathrm{C}$ to $22.4{ }^{\circ} \mathrm{C}$, the precipitation will decrease from $2100 \mathrm{~mm}$ to $1500 \mathrm{~mm}$ and the landscape water demand will increase. A nonlinear relationship exists between landscape water demand and temperature and precipitation. This SDUWMM simulation was conducted based on the existing data. When the temperature and precipitation exceed the scope of the existing data, the relationship between landscape water demand, temperature, and precipitation becomes uncertain.

\subsection{Scenario analysis}

The validated SDUWMM was used to calculate the water demands for different scenarios of population increase, economic growth, climate change, water conservation willingness, and water conservation measure applications in the future (2013-2022) in Macau. The detailed settings of the four scenarios are shown in Table 2. Scenario (a) represents the situation with the maximum population growth rate and a relatively low economic growth rate, low water conservation willingness, and without any conservation measures. Scenario (b) keeps the same society development pattern from 2012 with a GDP growth rate of $9.1 \%$, a maximum population of 528,000, lower water conservation willingness, and without any conservation measures. Scenario (c) is a scenario where society develops rapidly. It has the maximum population, the highest GDP growth rate, low water conservation willingness, and without any conservation measures. Scenario (d) keeps the same society status as scenario (c), and incorporates water conservation measures and improved water conservation willingness. In scenario (d), the pipeline leakage rate is set to decrease by $0.1 \%$ per year (Macau Water Report, 2010-2011), the saving rate of water-saving appliances is set to be $70 \%$, and the residents' DWDC $_{t}$ caused by water conservation willingness is set to be $2 \%$ more than the 
lower water conservation willingness situation.

The calculated water demand results for these four scenarios are shown in Fig. 8. The highest water demand will reach $11.0 \times 10^{7} \mathrm{~m}^{3}$ by the year of 2022 for scenario (c). The lowest water demand is $9.075 \times 10^{7} \mathrm{~m}^{3}$ for scenario $(\mathrm{d})$.

The low economic development scenario (a) is compared with the fast society development scenario (c): the water demand for scenario (c) is lower than that for the low economic development scenario (a) during the earlier simulation years of 2013 to 2021. This is caused by there being $500 \mathrm{~mm}$ more precipitation in scenario (c) than in (a). The $4.1 \%$ relative increase in GDP in scenario (c) ultimately resulted in the highest water demand in 2022. The water demand increase rates are similar for these two scenarios.

Comparing the low maximum population scenario (b) with the rapid society development scenario (c), the water demand of scenario (b) is always lagging far behind that of scenario (c), even though scenario (b) has $500 \mathrm{~mm}$ less precipitation than scenario (c). Compared with scenario (c), scenario (b) has $7.23 \%$ less water demand in 2022. This demonstrates that population is the major driving force for water demand increase and that precipitation is a relatively minor factor. Controlling population growth is an effective way to control water demand in Macau.

Comparing the rapid society development scenario (c) with the water conservation scenario (d), integrated water conservation measures show a clear positive effect on reducing water demand. Because scenario (c) and (d) have the same society development settings and climate conditions, the large water demand reduction in scenario (d) of up to $17.5 \%$ is solely caused by the integrated water conservation measures in scenario (d).

\section{Conclusions}

The SDUWMM was proposed in this study to investigate the dynamic relationships between urban water demand and the influencing factors of society, economy, and climate. A new, virtual, parameter for residents' water conservation willingness was incorporated in the improved system dynamic model to evaluate the improved water use efficiency for the urban water system. Population factors were found to be the main driving force for urban water demand in the model. Among the various input variables, population, per capita demand, and temperature were found to be the most sensitive parameters for the output of water demand. Four different scenarios with different society development, climate conditions, and water conservation measures were simulated for Macau's water demand for 2013 to 2022. The total 
water demand could be reduced by $17.5 \%$ if integrated water conservation measures are implemented. In order to reach a sustainable development pattern in Macau, the government should focus on controlling population growth, increasing residents' water conservation awareness, and improving water-use efficiency and wastewater reuse.

\section{Acknowledgments}

This research is supported by the MYRG072 (Y1-L2)-FST13-LIC, the National Science Foundation of China (No. 51278054), the Fund for Innovative Research Group of the National Natural Science Foundation of China (No. 51421065), and the State Key Program of National Natural Science of China (No. 41530635) . The authors are grateful to their supports

\section{References}

Ahmad, S.D., Prashar., 2010. Evaluating Municipal Water Conservation Policies Using a Dynamic Simulation Model. Water Resour. Manage. 24(13), 3371-3395.

An, I.Y., Lee, Y.L., Kim, J.H., 2014. A study of the characteristics of a super water-saving toilet with flexible trapway by measuring accumulated flow rate. J. Mechanical Sci. Tech. 28, 3067-3074.

Bao, C., Fang, C.-1., 2011. Water Resources Flows Related to Urbanization in China: Challenges and Perspectives for Water Management and Urban Development. Water Resour. Manage. 26(2), 531-552.

Benchimol, J., 2015. Money in the production function: A new Keynesian DSGE perspective. Southern Econ. J. 82(1), $152-184$.

Cain, P.M., 2005. Modelling and forecasting brand share: A dynamic demand system approach. Int. J. Res. Mark. $22(2), 203-220$.

Cheng, H., Hu, Y., Zhao, J., 2009. Meeting China's Water Shortage Crisis: Current Practices and Challenges. Environ. Sci. Technol. 43, 240-244.

Chhatwal, J., He., T., 2015. Economic Evaluations with Agent-Based Modelling: An Introduction. Pharmaco Econ. 33, 423-433.

Chu, F. L. 2014. Using a logistic growth regression model to forecast the demand for tourism in las vegas. Tourism Manage. Perspectives. 12, 62-67.

Dawadi, S., Ahmad, S., 2012. Evaluating the impact of demand-side management on water resources under changing climatic conditions and increasing population. J. Environ. Manage. 114(2), 261-275.

DSEC, 2014. Macau Yearbook of Statistic. Driving Start Engine Consulting, Macau 2005, 2006, 2007, 2008, 
2009, 2010, 2011, 2012, 2013.

Eckert, S., Kohler. S., 2014. Urbanization and Health in Developing Countries: A Systematic Review. World Health \& Popul. 15(1), 7-20.

Fahs, H., Hayek, M., Fahs, M., Younes, A. 2013. An efficient numerical model for hydrodynamic parameterization in 2d fractured dual-porosity media. Advan. in Water Resour. 63(2), 179-193.

Forrester, J.W., 1961. Industrial Dynamics. MIT Press, Cambridge, MA.

Giuliani, M., Y. Li, M. Mainardi, C. Arias Munoz, A. Castelletti, Gandolfi, C., 2013. Co-adapting water demand and supply to changing climate in agricultural water systems, a case study in northern Italy. Agu Fall Meeting,

Grafton, R.Q., Ward, M.B., To, H., Kompas, T., 2011. Determinants of residential water consumption: Evidence and analysis from a 10-country household survey. Water Resour. Res. 47 W08537, 1-14

Haque, M. M., Egodawatta, P., Rahman, A., Goonetilleke, A. 2015. Assessing the significance of climate and community factors on urban water demand. Int. J. Sustainable Built Environ. 4(2), 222-230.

House-Peters, L. A., Chang, H., 2011. Urban water demand modeling: Review of concepts, methods, and organizing principles. Water Resour. Res. 47(5), W05401

Humpenoder, F., Popp, A., Stevanovic, M., Muller, C., Bodirsky, B.L., Bonsch, M., et al., 2015. Land-use and carbon cycle responses to moderate climate change: implications for land-based mitigation. Environ. Sci. Tecnonl. 49, 6731-6739.

Iglesias, A., Quiroga, S., Moneo, M., Garrote, L., 2011. From climate change impacts to the development of adaptation strategies: Challenges for agriculture in Europe. Climatic Change 112, 143-168.

Ilanit Tal, D.H., Aurelio Jos Figueredo, Martha Fras-Armenta, Corral-Verdugo, V., 2006. An evolutionary approach to explaining water conservation behavior. Medio Ambiente Y Comportamiento Humano. 7(1), $7-27$

Liu, C.-W., Thorp, J.S., 2000. New methods for computing power system dynamic response for real-time transient stability prediction. IEEE Transactions on Circuits and Systems I: Fundamental Theory and Applications, 47(3), 324-337.

Lin, Y.-H., Trethewey, M., 1990. Finite element analysis of elastic beams subjected to moving dynamic loads. J. Sound Vib. 136(2), 323-342.

Kanta, L., Zechman, E. M., 2014. A Mechanistic-Stochastic Approach to Classify Water Consumers and Simulate Urban Water Demand. World Environmental and Water Resources Congress 2013@sShowcasing 
the Future pp.2281-2290. ASCE.

Koch, H., Vögele, S., 2009. Dynamic modeling of water demand, water availability and adaptation strategies for power plants to global change. Ecol. Econ. 68 (7), 2031-2039.

Middelkoop, H., Daamen, K., Gellens, D., Grabs, W., Kwadijk, J. C. J., Lang, H., et al., 2001. Impact of climate change on hydrological regimes and water resources management in the rhine basin. Climatic Change. 49(1-2), 105-128.

Mokhtari, A., Benallegu, A., 2004. Dynamic feedback controller of Euler angles and wind parameters estimation for a quadrotor unmanned aerial vehicle. International Conference on Robotics and Automation. New Orieans, LA April 2004

National bureau of statistics., 2014. China Energy Statistical Yearbook. 2014. China Statistics Press.

Ping, Q., 2012. Discussion about current industrial water saving technology. Sci. Technol. of China. (20), 29-29. in Chinese

Qi, C., Chang, N.B., 2011. System dynamics modeling for municipal water demand estimation in an urban region under uncertain economic impacts. J. Environ. Manage. 92(6),1628-1641.

Qin, H.-P., Su, Q., Khu, S.-T. 2011. An integrated model for water management in a rapidly urbanizing catchment. Environ. Modell. Softw. 26(12), 1502-1514.

Refsgaard, JC ; van der Sluijs, J.P., Hojberg, A.L., Vanrolleghem, P.A., 2007. Uncertainty in the environmental modelling process - A framework and guidance. Environ. Modell. Softw. 22(11),1543-1556.

Rehan, R., Knight, M. A., Haas, C.T., Unger, A.J.A., 2011. Application of system dynamics for developing financially self-sustaining management policies for water and wastewater systems. Water Res. 45(16), 4737-50.

Rozos, E., Makropoulos, C., 2013. Source to tap urban water cycle modelling. Environ. Modell. Softw. 41(3), 139-150.

Sterman, J., 2000. Business dynamics: systems thinking and modeling for a complex world. J. Oper. Res. Soc. 34(100), 324-326.

Thomas, D., 2014. Understanding environmentally significant consumption. Proc. Nat. Acad. Sci. 111(14), 5067-8.

Vörösmarty, C.J., Green, P., Salisbury, J., Lammers, R.B., 2000. global water resources: vulnerability from climate change and population growth. Science. 289(5477), 284-292.

Wang, Y., Liu, L., 2007. Application of reclaimed water by micro-irrigation technique in urban greenland. 
Drain. Irrig. Machinery. 25(6), 31-33.

Wang, X.J., Zhang, J.Y., Ali, M., Shahid, S., He, R.M., Xia, X.H., et al., 2014. Impact of climate change on regional irrigation water demand in Baojixia irrigation district of China. Mitigation \& Adaptation Strategies for Global Change 20, 116-133.

Willis, R.M., Stewart, R.A., Panuwatwanich, K., Williams, P.R., Hollingsworth, A.L., 2011. Quantifying the influence of environmental and water conservation attitudes on household end use water consumption. J. Environ. Manage. 92(8), 1996-2009.

Wu, P., Tan., M., 2012. Challenges for sustainable urbanization: a case study of water shortage and water environment changes in Shandong, China. Procedia Environ. Sci. 13(3), 919-927.

Wu, X., Zhou, J., Wang, H., Li.Y., Zhong, B., 2015. Evaluation of irrigation water use efficiency using remote sensing in the middle reach of the Heihe river, in the semi-arid Northwestern China. Hydrol. Processes. 29, $2243-2257$

\section{List of figures}

Fig.1 A schematic layout of system dynamics urban water management model (SDUWMM).

Fig.2 The structure of the SDUWMM.

Fig.3 Map of Macau with major water infrastructures.

Fig.4 The change of main influential factors of Macau from 2006 to 2012.

Fig. 5 Comparison of the simulated water demand with the observed water consumption for Macau.

Fig.6 Sensitivity analysis of water demand changing with main driving forces in 2006.

Fig.7 Simulated results of landscape water demand together with the recorded data.

Fig.8 The simulation results of the four scenarios. 


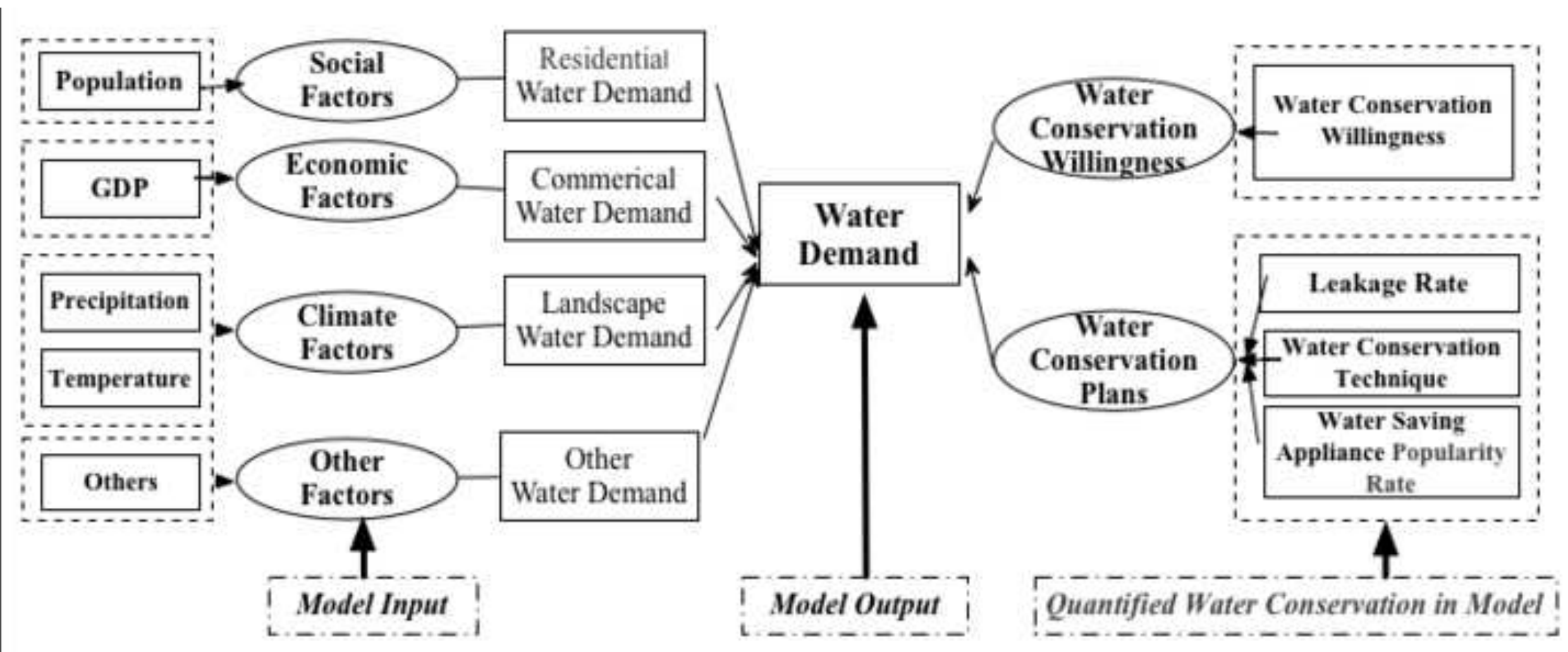

\section{Legend}

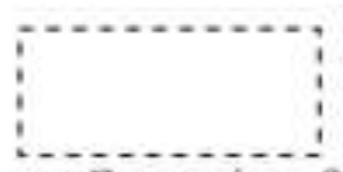

Different Categories of the Variables

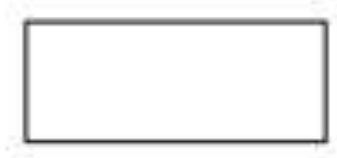

Variables in the Model

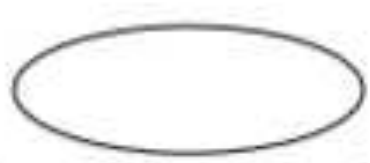

Name of the Categories of Variables

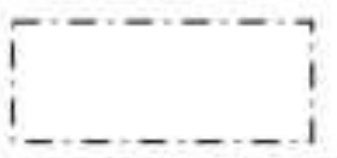

Different Categories of the Input Variables 


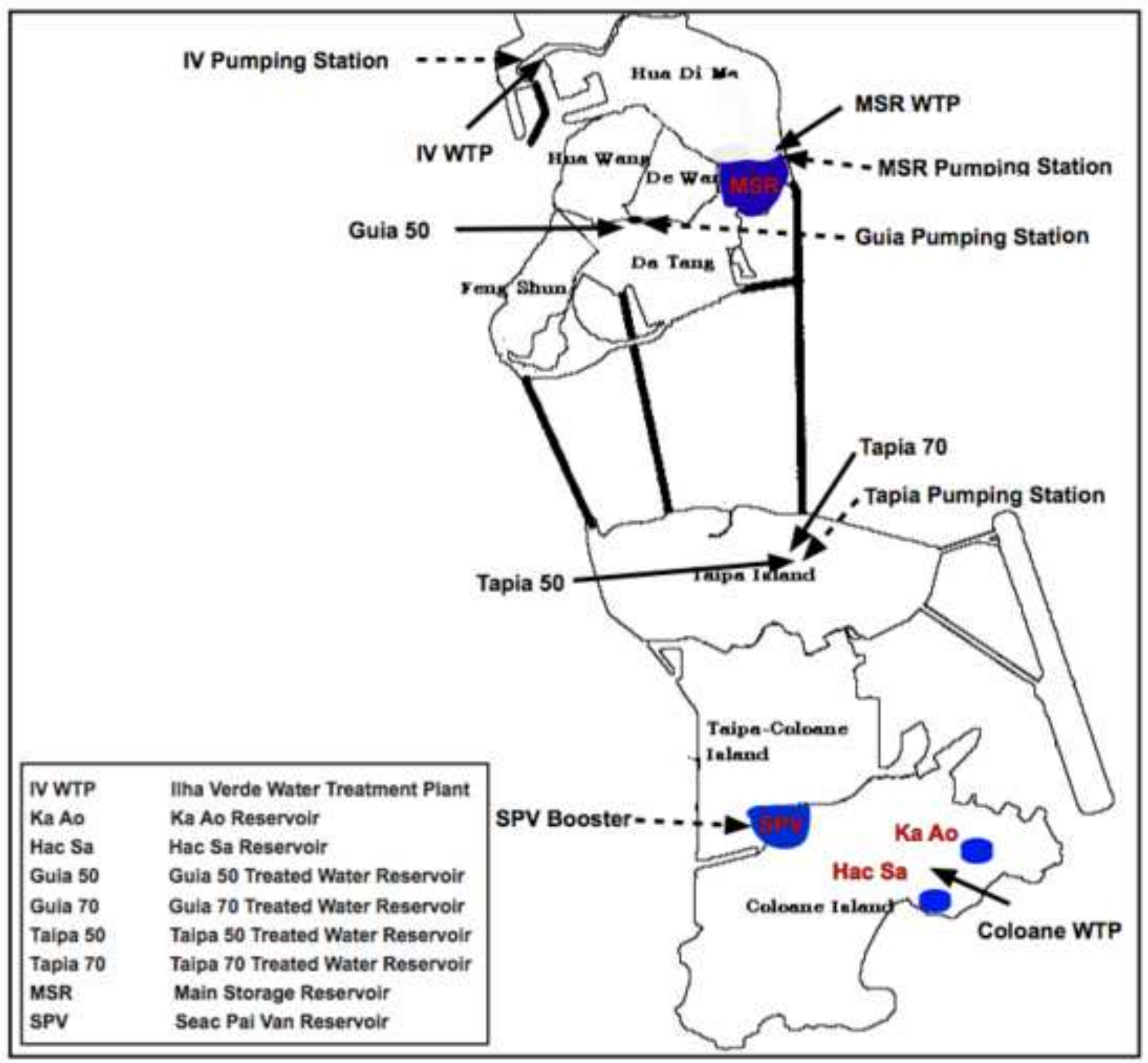


$\rightarrow$ Population $\left(10^{5}\right) \rightarrow$ Precipitation $\left(10^{2} \mathrm{~mm}\right)$

$\rightarrow \operatorname{GDP}\left(10^{10} \mathrm{MOP}\right) \rightarrow$ Temperature $\left({ }^{\circ} \mathrm{C}\right)$

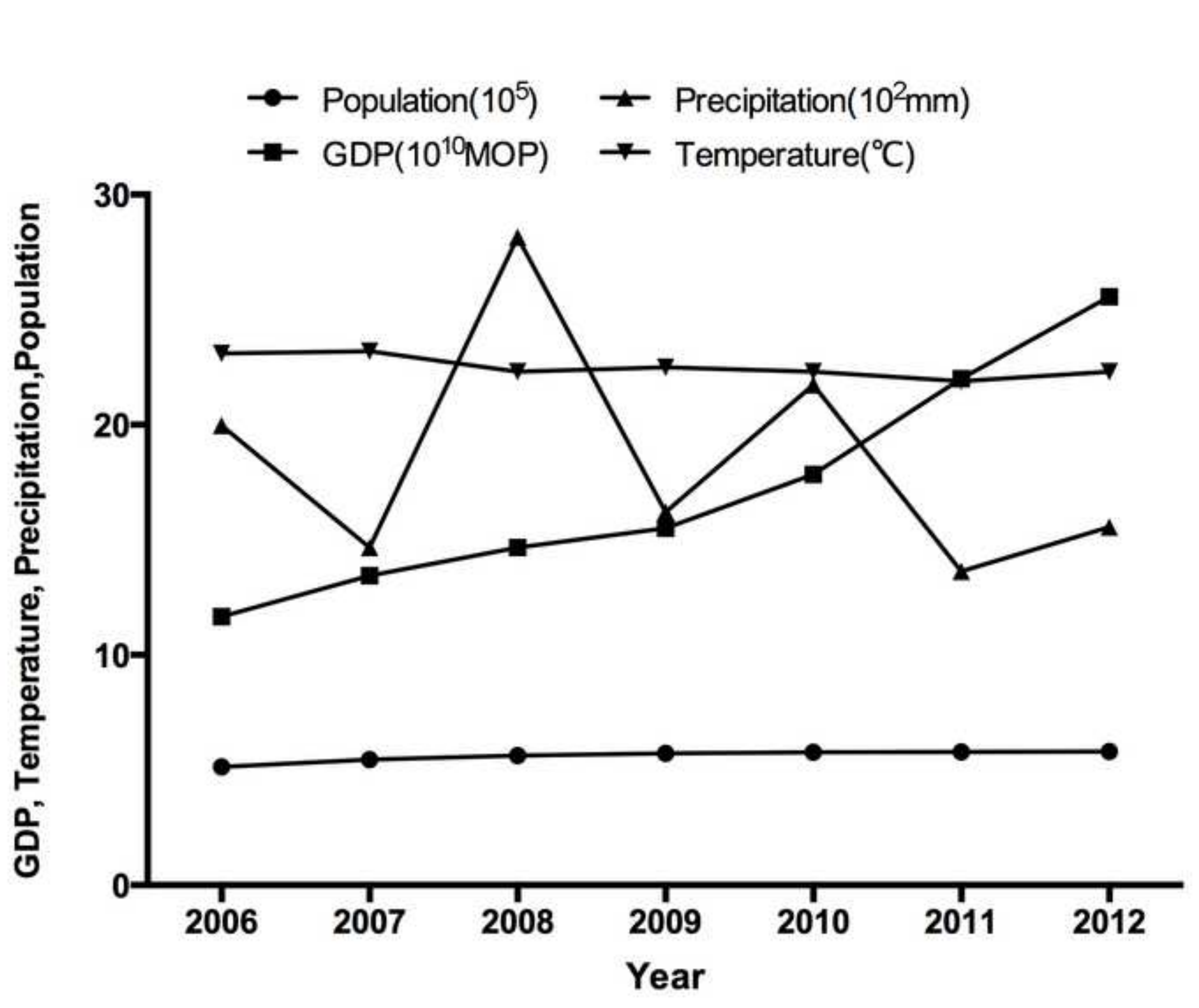


$\rightarrow$ Total Observed Consumption

-다- Total Simulated Demand

- Commenical Observed Consumption- L Landscape Observed Consumption

-1- Commerical Simulated Demand - - L Landscape Simulated Demand $\longrightarrow$ Residential Observed Consumption

-6- Residential Simulated Demand

है

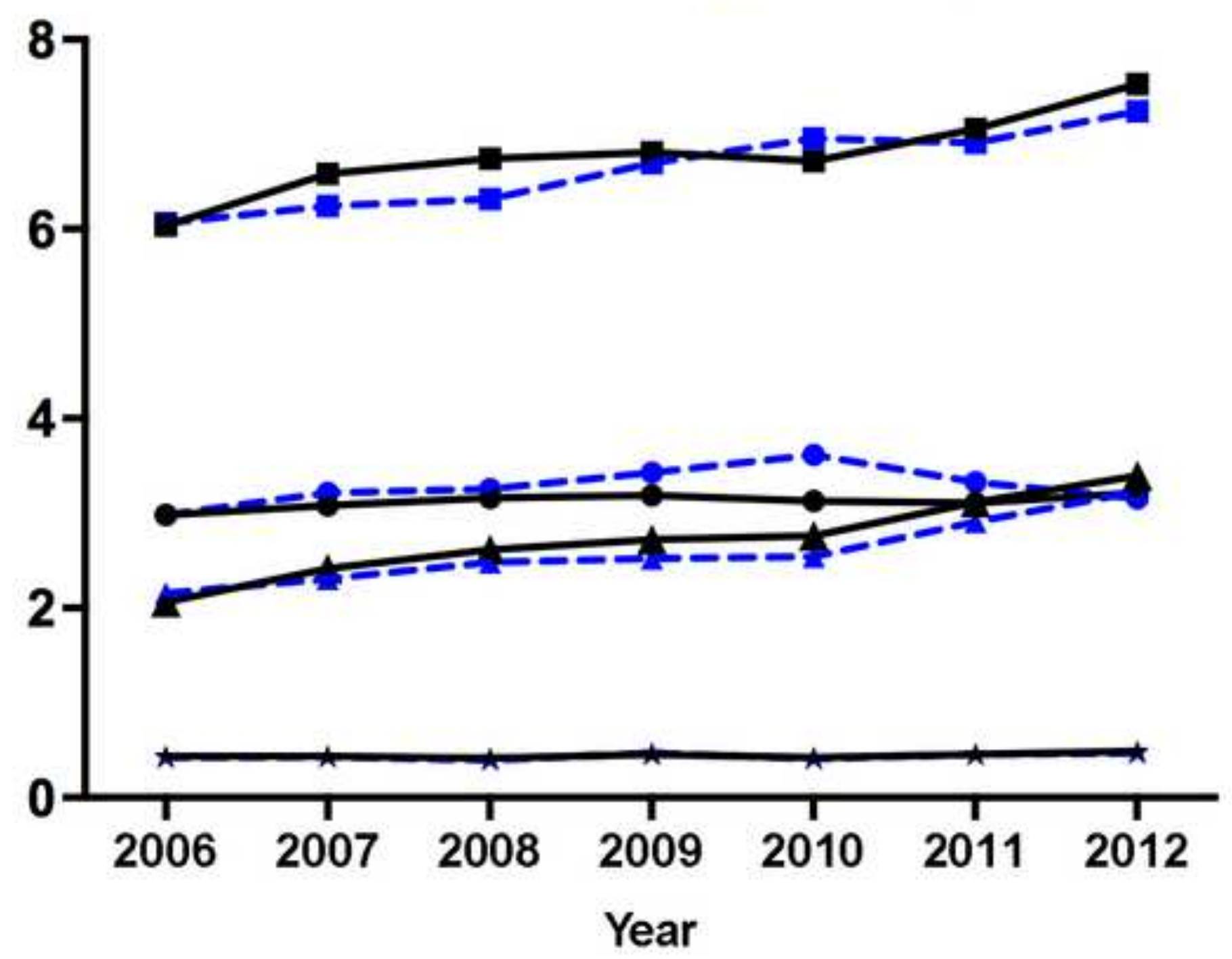




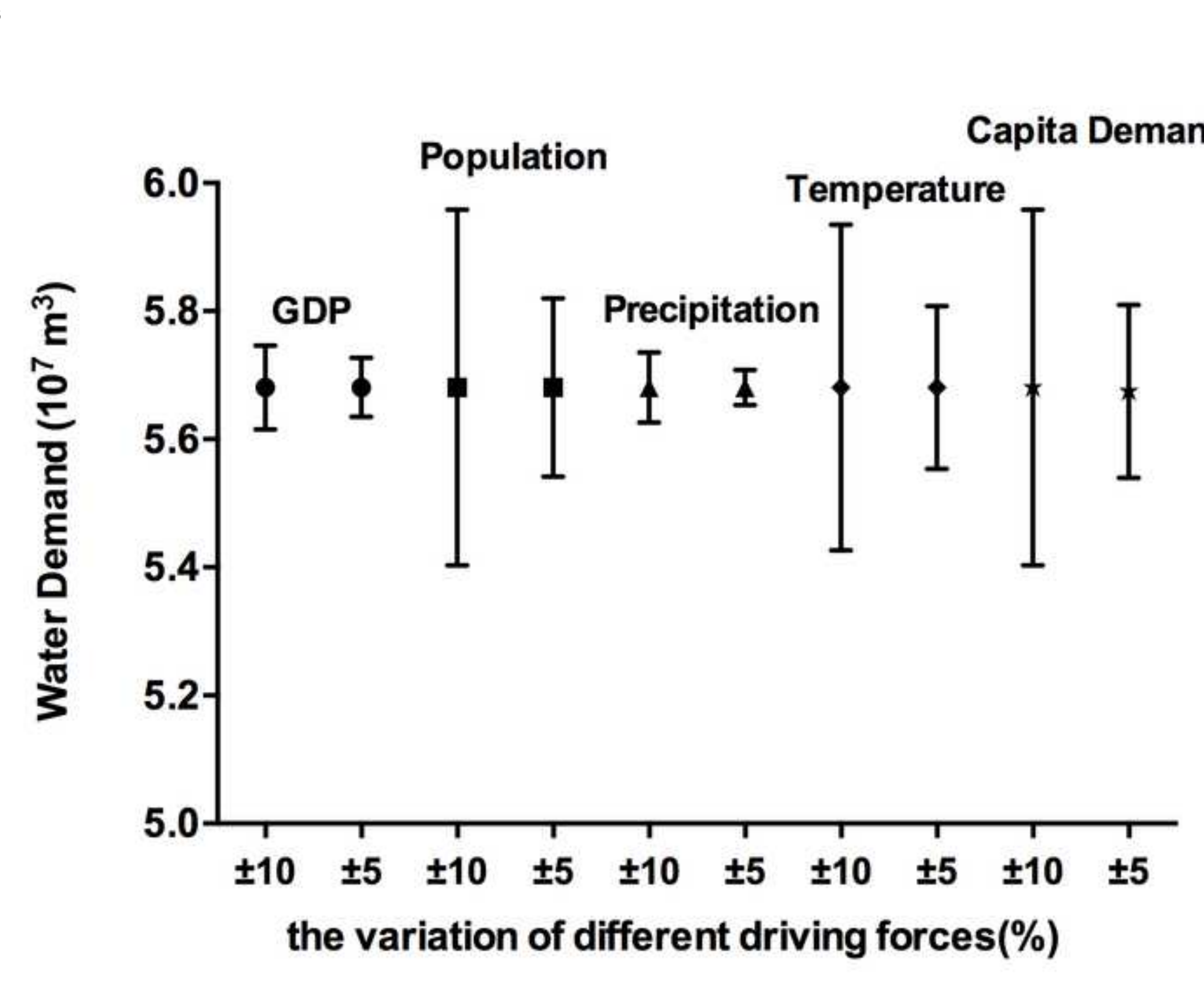

\section{d}

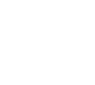

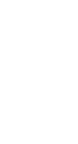




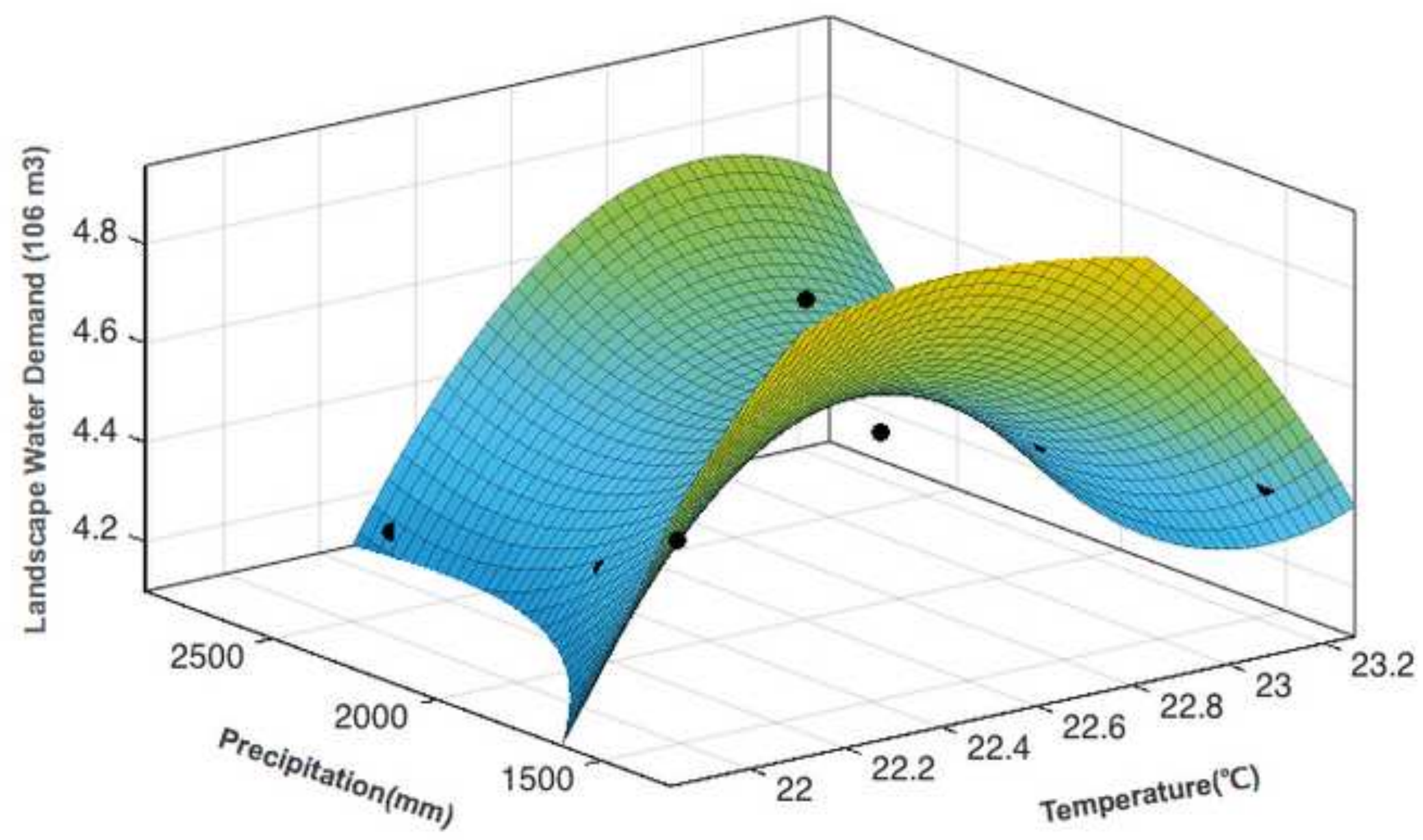




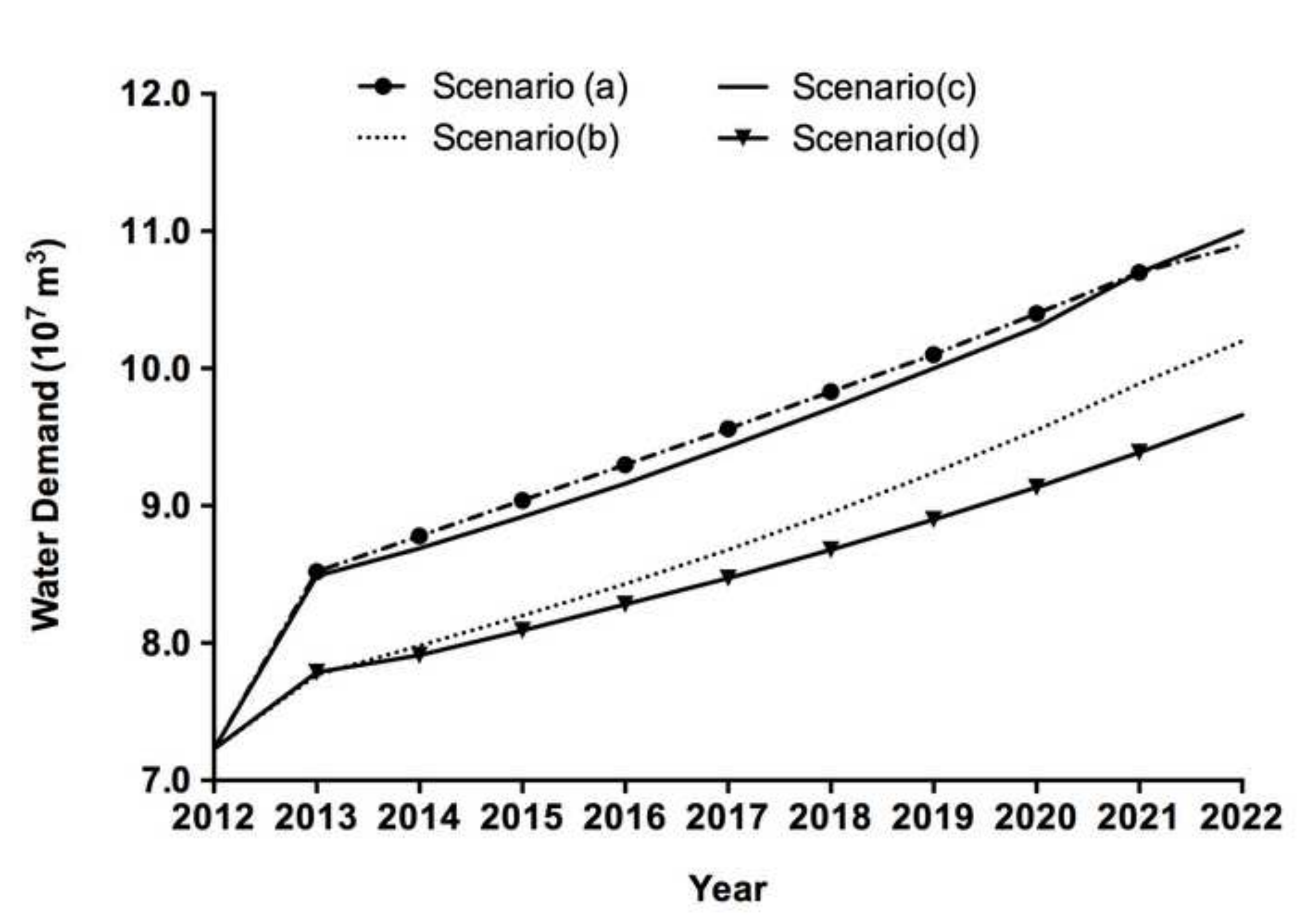

\section{Year}

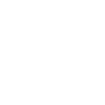


Table 1 Validation results of different water demand categories.

\begin{tabular}{ccccccccc}
\hline \multirow{2}{*}{ Year } & \multicolumn{2}{c}{ Total water demand } & \multicolumn{2}{c}{$\begin{array}{c}\text { Commercial water } \\
\text { demand }\end{array}$} & \multicolumn{2}{c}{$\begin{array}{c}\text { Residential water } \\
\text { demand }\end{array}$} & \multicolumn{2}{c}{$\begin{array}{c}\text { Landscape water } \\
\text { demand }\end{array}$} \\
\cline { 2 - 9 } & $M(\%)$ & $E(\%)$ & $M(\%)$ & $E(\%)$ & $M(\%)$ & $E(\%)$ & $M(\%)$ & $E(\%)$ \\
\hline 2006 & 2.01 & 1.97 & 4.50 & 4.66 & 0.00 & 0.00 & 2.28 & 2.33 \\
2007 & 3.56 & 5.21 & 4.29 & 4.85 & 4.32 & 4.47 & 1.26 & 1.81 \\
2008 & 4.95 & 6.38 & 5.10 & 5.81 & 3.14 & 3.29 & 3.85 & 4.91 \\
2009 & 0.01 & 0.01 & 7.28 & 8.49 & 7.65 & 7.67 & 1.99 & 2.25 \\
2010 & 5.02 & 5.35 & 7.95 & 9.33 & 15.60 & 14.58 & 2.14 & 2.45 \\
2011 & 1.88 & 2.1 & 6.57 & 7.60 & 7.16 & 7.22 & 0.3 & 0.33 \\
2012 & 4.01 & 4.51 & 4.96 & 5.64 & 1.98 & 2.18 & 4.97 & 5.65 \\
\hline
\end{tabular}

$M$ : maximum relative error; $E$ : mormalized standard error.

Table 2 Detail settings of the four scenarios.

\begin{tabular}{|c|c|c|c|c|c|}
\hline Scenarios & $\begin{array}{l}\text { GDP growth } \\
\text { rate }\left(r_{\mathrm{g}}\right)(\%)\end{array}$ & $\begin{array}{c}\text { Maximum } \\
\text { population } \\
(P(t)) \text { (capita) }\end{array}$ & $\begin{array}{c}\text { Temperature } \\
(T(t))\left({ }^{\circ} \mathrm{C}\right)\end{array}$ & $\begin{array}{l}\text { Precipitation } \\
\left(P_{\mathrm{r}}(t)\right)(\mathrm{mm})\end{array}$ & $\begin{array}{l}\text { Water conservation } \\
\text { measures }\end{array}$ \\
\hline $\mathrm{a}$ & 5.00 & 700,000 & 22.3 & 1500 & $\begin{array}{c}\text { Lower water conservation } \\
\text { willingness }\end{array}$ \\
\hline b & 9.10 & 582,000 & 22.3 & 1500 & $\begin{array}{c}\text { Lower water conservation } \\
\text { willingness }\end{array}$ \\
\hline $\mathrm{c}$ & 9.10 & 700,000 & 22.3 & 2000 & $\begin{array}{c}\text { Lower water conservation } \\
\text { willingness }\end{array}$ \\
\hline d & 9.10 & 700,000 & 22.3 & 2000 & $\begin{array}{c}\text { Improved water } \\
\text { conservation willingness, } \\
\text { water conservation } \\
\text { measures }\end{array}$ \\
\hline
\end{tabular}

